\title{
Actinomycetes: The Antibiotics Producers
}

\author{
Yvonne Mast $1,2,3,4, * \mathbb{C}$ and Evi Stegmann ${ }^{3,4, *}$ \\ 1 Department of Bioresources for Bioeconomy and Health Research, Leibniz Institute DSMZ-German Culture \\ Collection for Microorganisms and Cell Cultures, 38124 Braunschweig, Germany \\ 2 Institute for Microbiology, Technical University of Braunschweig, 38106 Braunschweig, Germany \\ 3 Department of Microbiology/Biotechnology, Interfaculty Institute of Microbiology and Infection Medicine, \\ Faculty of Science, Eberhard Karls University of Tübingen, Auf der Morgenstelle 28, \\ D-72076 Tübingen, Germany \\ 4 German Center for Infection Research (DZIF), Partner Site Tübingen, D-72076 Tübingen, Germany \\ * Correspondence: yvonne.mast@dsmz.de (Y.M.); evi.stegmann@biotech.uni-tuebingen.de (E.S.); \\ Tel.: +49-(0)-531-2616-418 (Y.M.); +49-(0)-7071-2978-840 (E.S.)
}

Received: 12 July 2019; Accepted: 25 July 2019; Published: 29 July 2019

Actinomycetes are well known as an inexhaustible source for antibiotics. Most of the known antimicrobials today were originally isolated from actinomycetes, especially from the genus Streptomyces. The produced substances include all important drug classes used in clinics today, such as $\beta$-lactams, tetracyclines, macrolides, aminoglycosides, or glycopeptides. However, in the past years the effectiveness of these impressive weapons have become endangered by the rise of resistances of live-threatening pathogenic bacteria. In addition to that, the golden era of antibiotic discovery has been over for quite a while and the antibiotic pipeline was feared to run dry. Next-generation sequencing techniques in combination with genome mining approaches revolutionized the field of antibiotic research and might reboot the pipeline in the near future. In 2002, the first Streptomyces genome sequence was published [1]. This was the genome sequence of the model actinomycete Streptomyces coelicolor. Mining this sequence revealed that $S$. coelicolor harbors 22 secondary metabolite gene clusters but indeed produces only four of the encoded metabolites under standard lab conditions. Currently, more than 625 genome sequences are available only of the genus Streptomyces [2]. Genome mining analyses suggest that less than $10 \%$ of the genetic potential of antibiotic producers is currently being used [3], which implicates that there is a huge untapped genetic reservoir waiting to be exploited for drug discovery. In addition to that, metagenomic data indicate that there are far more potential antibiotic producers in nature awaiting isolation and investigation. Thus, today, almost 80 years after Selman Waksman introduced the genus of Streptomyces and, with actinomycin being the first antibiotic that was isolated from an actinomycete, these bacteria still represent a treasure chest for the identification of novel antibiotics.

Novel cultivation strategies, elaborated screening techniques, new genetic manipulation tools, further insights into physiological aspects of actinobacterial live style, and also knowledge on new secondary metabolite biosynthetic pathways may open up a new era of antibiotic drug discovery.

In the Special Issue of "Actinomycetes: The Antibiotics Producers" we will highlight the latest research findings in the field. The current issue brings together 19 publications (9 research articles and 10 reviews) from expert groups, which address scientific topics associated with the biology of actinomycetes as well as their antibiotic biosynthesis capacity.

Two research articles deal with the isolation and characterization of actinobacteria from unique habitats. Using a high-throughput sequencing approach, Maciejewska et al. were able to show that there is a quite complex actinobacterial community present in cave moonmilk deposits obtained from the cave "Grotte des Collemboles", Belgium [4]. By applying several strategies to allow growth and isolation of hard-to-culture actinobacteria, Adam et al. were able to isolate new actinobacterial representatives 
from these cave moonmilk deposits and demonstrated that some of them exert antibacterial activity [5]. Another extraordinary source for novel actinobacteria producing unique chemistry are certain insects. Benndorf et al. isolated 97 actinobacteria from the fungus-growing termite Macrotermes natalensis and analyzed them in terms of their antibiotic production properties. Thereby, the authors isolated several new actinobacterial species and identified a dichlorinated diketopiperazine derivative and two tetracyclic lanthipeptides (rubrominins A and B) as new secondary metabolites [6]. However, not just new strain isolates but also old strain isolates can be promising sources for novel natural compounds, when investigated with state-of the art analytical technologies. This has been effectively highlighted in the review of Takahashi and Nakashima, which gives an update on novel compounds from old strains of the Kitasato Microbial Library [7]. Indeed, the authors describe the identification of 36 novel compounds from 11 actinomycetes, most of them more than 35 years old. Thereby, the list of producers resembles a quite diverse set of actinomycetes, which illustrates that also non-Streptomyces actinomycetes represent good sources for novel natural compounds. This is also underpinned by the study of Iorio et al., which specifically focusses on the underexplored genus Actinoallumurus, for which two novel polyether substances ( $\alpha-770$ and $\alpha-823)$ were described [8]. This raises the question if and to what extent gene cluster composition differs between different types of actinobacterial antibiotic producers. Two of the Journal's papers deal with that issue in more detail: Choudoir et al. and Vicente et al. focus on comparative biosynthetic gene cluster (BGC) distributions in similar streptomycetes and thereby concentrate on the evolutionary dynamics of BGCs within these organisms [9,10]. These manuscripts already depict the importance of omics approaches in antibiotic research, which in general is shortly highlighted in the review of Genilloud [11]. Finally, a very comprehensive review on novel strategies and innovative methods to get access to novel natural compounds from actinomycetes is given by Hug et al., which also offers a very reasonable outlook to future perspectives in antibiotic research [12].

Besides the studies that aim to identify novel antibiotics, the Special Issue also contains four papers dealing with specific antibiotics and their biosyntheses: Schwarzer et al. report on the biosynthesis of the polyketide rishirilide B [13], whereas Hofeditz et al. describe the production and structure elucidation of the novel polyphenolic tridecaketide lysoquinone-TH1 [14]. Both compounds are polyketides, and biosynthesis has successful been made possible after heterologous expression of the respective gene clusters in Streptomyces albus. Viana Marques et al. provide an update on $\beta$-lactam inhibitors and their applications [15], whereas Musiol-Kroll and Wohlleben focus on the biochemical function and usage of acyltransferases during polyketide biosynthesis for engineering approaches [16].

Especially when it comes to engineering and production attempts of the respective compounds, regulation and self-resistance of the producer organisms are important factors to be targeted in order to increase yields. Thus, aspects of regulation and self-resistance are also addressed in the Special Issue: Ordóñez-Robles et al. summarize the current knowledge on regulation of tacrolimus biosynthesis in Streptomyces tsukubaensis [17]. Alduina et al. report on the regulatory network influencing the biosynthesis of the glycopeptide antibiotic A40926 from Nonomuraea sp. [18], whereas Binda et al. concentrate on the self-resistance mechanisms and characteristics of glycopeptide producers in general [19].

Besides their overwhelming importance as antibiotic producers, actinomycetes undoubtedly have further imposing characteristics, and some of them are handled in the Special Issue. For example, actinomycetes undergo a complex life cycle, whereby morphological development and secondary metabolism often coincide. Manteca and Yagüe review strategies to improve Streptomyces differentiation in liquid cultures with the aim to elicit antibiotic production [20]. Furthermore, actinomycetes are well known as potent producers of extracellular hydrolytic enzymes, which is relevant for industrial applications. Here, Gullón and Mellado give an overview focusing on the secretion machinery of the most widely used host strains for exoenzyme production-Streptomyces lividans [21]. Finally, Jones reports on known and novel aspects of the polynucleotide phosphorylase (PNPase) in Streptomyces, which exerts a dual function as $3^{\prime}-5^{\prime}$-exoribonuclease and RNA $3^{\prime}$-polyribonucleotide polymerase [22]. 
We are happy to bring together so many valuable works from respected experts in the field. It was our great pleasure to be Guest Editors of this special issue of Antibiotics.

Author Contributions: Y.M. and E.S. equally contributed in writing the article.

Funding: This research received funding from the German Center for Infection research (DZIF), TTU 09.819.

Conflicts of Interest: The authors declare no conflicts of interest."

\section{References}

1. Bentley, S.D.; Chater, K.F.; Cerdeño-Tárraga, A.M.; Challis, G.L.; Thomson, N.R.; James, K.D.; Harris, D.E.; Quail, M.A.; Kieser, H.; Harper, D.; et al. Complete genome sequence of the model actinomycete Streptomyces coelicolor A3(2). Nature 2002, 417, 141-147. [CrossRef] [PubMed]

2. Blin, K.; Pascal Andreu, V.; de Los Santos, E.L.C.; Del Carratore, F.; Lee, S.Y.; Medema, M.H.; Weber, T. The antiSMASH database version 2: A comprehensive resource on secondary metabolite biosynthetic gene clusters. Nucleic Acids Res. 2019, 47, D625-D630. [CrossRef] [PubMed]

3. Nett, M.; Ikeda, H.; Moore, B.S. Genomic basis for natural product biosynthetic diversity in the actinomycetes. Nat. Prod. Rep. 2009, 26, 1362-1384. [CrossRef] [PubMed]

4. Maciejewska, M.; Całusińska, M.; Cornet, L.; Adam, D.; Pessi, I.S.; Malchair, S.; Delfosse, P.; Baurain, D.; Barton, H.A.; Carnol, M.; et al. High-Throughput Sequencing Analysis of the Actinobacterial Spatial Diversity in Moonmilk Deposits. Antibiotics 2018, 7, 27. [CrossRef] [PubMed]

5. Adam, D.; Maciejewska, M.; Naômé, A.; Martinet, L.; Coppieters, W.; Karim, L.; Baurain, D.; Rigali, S. Isolation, Characterization, and Antibacterial Activity of Hard-to-Culture Actinobacteria from Cave Moonmilk Deposits. Antibiotics 2018, 7, 28. [CrossRef] [PubMed]

6. Benndorf, R.; Guo, H.; Sommerwerk, E.; Weigel, C.; Garcia-Altares, M.; Martin, K.; Hu, H.; Küfner, M.; de Beer, Z.W.; Poulsen, M.; et al. Natural Products from Actinobacteria Associated with Fungus-Growing Termites. Antibiotics 2018, 7, 83. [CrossRef] [PubMed]

7. Takahashi, Y.; Nakashima, T. Actinomycetes, an Inexhaustible Source of Naturally Occurring Antibiotics. Antibiotics 2018, 7, 45. [CrossRef] [PubMed]

8. Iorio, M.; Tocchetti, A.; Santos Cruz, J.C.; Del Gatto, G.; Brunati, C.; Maffioli, S.I.; Sosio, M.; Donadio, S. Novel Polyethers from Screening Actinoallomurus spp. Antibiotics 2018, 7, 47. [CrossRef] [PubMed]

9. Choudoir, M.J.; Pepe-Ranney, C.; Buckley, D.H. Diversification of Secondary Metabolite Biosynthetic Gene Clusters Coincides with Lineage Divergence in Streptomyces. Antibiotics 2018, 7, 12. [CrossRef]

10. Vicente, C.M.; Thibessard, A.; Lorenzi,J.N.; Benhadj, M.; Hôtel, L.; Gacemi-Kirane, D.; Lespinet, O.; Leblond, P.; Aigle, B. Comparative Genomics among Closely Related Streptomyces Strains Revealed Specialized Metabolite Biosynthetic Gene Cluster Diversity. Antibiotics 2018, 7, 86. [CrossRef]

11. Genilloud, O. Mining Actinomycetes for Novel Antibiotics in the Omics Era: Are We Ready to Exploit This New Paradigm? Antibiotics 2018, 7, 85. [CrossRef] [PubMed]

12. Hug, J.J.; Bader, C.D.; Remškar, M.; Cirnski, K.; Müller, R. Concepts and Methods to Access Novel Antibiotics from Actinomycetes. Antibiotics 2018, 7, 44. [CrossRef] [PubMed]

13. Schwarzer, P.; Wunsch-Palasis, J.; Bechthold, A.; Paululat, T. Biosynthesis of Rishirilide, B. Antibiotics 2018, 7, 20. [CrossRef] [PubMed]

14. Hofeditz, T.; Unsin, C.E.; Wiese, J.; Imhoff, J.F.; Wohlleben, W.; Grond, S.; Weber, T. Lysoquinone-TH1, a New Polyphenolic Tridecaketide Produced by Expressing the Lysolipin Minimal PKS II in Streptomyces albus. Antibiotics 2018, 7, 53. [CrossRef] [PubMed]

15. Viana Marques, D.A.; Machado, S.E.F.; Ebinuma, V.C.S.; Duarte, C.A.L.; Converti, A.; Porto, A.L.F. Production of $\beta$-Lactamase Inhibitors by Streptomyces Species. Antibiotics 2018, 7, 61. [CrossRef] [PubMed]

16. Musiol-Kroll, E.M.; Wohlleben, W. Acyltransferases as Tools for Polyketide Synthase Engineering. Antibiotics 2018, 7, 62. [CrossRef] [PubMed]

17. Ordóñez-Robles, M.; Santos-Beneit, F.; Martín, J.F. Unraveling Nutritional Regulation of Tacrolimus Biosynthesis in Streptomyces tsukubaensis through omic Approaches. Antibiotics 2018, 7, 39. [CrossRef] [PubMed]

18. Alduina, R.; Sosio, M.; Donadio, S. Complex Regulatory Networks Governing Production of the Glycopeptide A40926. Antibiotics 2018, 7, 30. [CrossRef] 
19. Binda, E.; Cappelletti, P.; Marinelli, F.; Marcone, G.L. Specificity of Induction of Glycopeptide Antibiotic Resistance in the Producing Actinomycetes. Antibiotics 2018, 7, 36. [CrossRef]

20. Manteca, Á.; Yagüe, P. Streptomyces Differentiation in Liquid Cultures as a Trigger of Secondary Metabolism. Antibiotics 2018, 7, 41. [CrossRef]

21. Gullón, S.; Mellado, R.P. The Cellular Mechanisms that Ensure an Efficient Secretion in Streptomyces. Antibiotics 2018, 7, 33. [CrossRef] [PubMed]

22. Jones, G.H. Novel Aspects of Polynucleotide Phosphorylase Function in Streptomyces. Antibiotics 2018, 7, 25. [CrossRef] [PubMed]

(C) 2019 by the authors. Licensee MDPI, Basel, Switzerland. This article is an open access article distributed under the terms and conditions of the Creative Commons Attribution (CC BY) license (http://creativecommons.org/licenses/by/4.0/). 